\title{
SARS-CoV-2 seroprevalence and antibody trends in vaccinated, multi-ethnic healthcare employees
}

\author{
Beh, C.C. ${ }^{1}$, Zulkufli, N.S. ${ }^{1 *}$, Loh, L.M. ${ }^{1}$, Cheng, K.W. ${ }^{1}$, Choo, L.M. ${ }^{1}$, Cheah, M.W. ${ }^{1}$, Siow, L.K. ${ }^{2}$, Yon, R. ${ }^{1}$ \\ ${ }^{1}$ BP Clinical Lab Sdn Bhd, Temasya@Glenmarie, Lot 2, Jalan Pendaftar U1/54, Section U1, 40150 Shah Alam, Selangor, Malaysia \\ ${ }^{2}$ Lovy Pharmacy Sdn Bhd, 79, Jalan SS 23/15, Taman SEA, 47400 Petaling Jaya, Selangor, Malaysia \\ *Corresponding author: drnadasyazana@bphealthcare.com
}

\section{ARTICLE HISTORY}

Received: 10 Nov 2021

Revised: 22 November 2021

Accepted: 22 November 2021

Published: 31 December 2021

\begin{abstract}
Understanding of antibody kinetics against SARS-CoV-2 and its vaccines is rapidly evolving. This study aims to (1) determine post-vaccination seroprevalence; (2) compare antibody levels between vaccine types and various clinical/demographic determinants; and (3) determine post-vaccination antibody concentrations against time. This is a retrospective cross-sectional study involving 148 healthcare employees all over Malaysia. IgG Spike (RBD), IgM Spike and IgG Nucleocapsid concentration medians were compared using Mann-Whitney $\mathrm{U}$ or Kruskal-Wallis tests. Chi Square and Spearman correlation coefficient tests were performed to identify variables associated with antibody titers. A scatter plot of IgG Spike (RBD) against time from last vaccine dose was also plotted. At 1-month post-vaccination, all employees successfully seroconverted regardless of vaccine type, health status and COVID19 history. Comirnaty, convalescent, female or Malay vaccinees had significantly higher IgG Spike (RBD) titers compared to their respective counterparts. No correlation was found between age and IgG Spike (RBD) levels. Concentration of all three antibodies waned with time post-vaccination, with IgM Spike and IgG Nucleocapsid waning faster than IgG Spike (RBD).
\end{abstract}

Keywords: SARS-CoV-2; COVID-19; antibodies; vaccine; seroprevalence.

\section{INTRODUCTION}

COVID-19 remains to be a global pandemic that significantly impacts on healthcare and economic systems worldwide. As part of control efforts, governments have rolled out vaccination programs and initiated serologic testing to determine the population's seroprevalence. Positive seroconversion from infection has been reported to confer up to $90 \%$ protection from reinfection whilst vaccine efficacies range from 50-95\% (Khoury et al., 2021). However, long-term antibody protection against re-infection following COVID-19 and/or vaccination is still poorly understood. There is currently mixed evidence on the evolution of antibody titers post-exposure ranging from 3 months to 1 year, possibly due to the heterogeneous populations studied, measuring assays employed, viral variants and vaccine types (Baraniuk, 2021; Blain et al., 2021; Edara et al., 2021; Khoury et al., 2021). At the moment, the Centers for Disease Control and Prevention (CDC) do not recommend the use of antibody testing as a means of assessing immunity peri-vaccination nor a diagnostic tool for COVID-19 (CDC, 2021).

The SARS-CoV-2 entry into host cells is mediated by an interaction between its receptor binding domain (RBD) on the Spike protein to the angiotensin-converting enzyme 2 (ACE 2) receptor on the host cell ( $\mathrm{Ni}$ et al., 2020). For this reason, the Spike protein has been made a target for vaccine modelling and serological testing to determine past infection or vaccination. In addition to the Spike protein, Nucleocapsid, an abundant protein within the SARS-CoV-2 involved in genome packaging, is also a serological target where Nucleocapsid antibodies are used to indicate past infection and vaccination with inactivated virus (Bai et al., 2021; CDC, 2021).

With rapidly emerging evidence and high uptake of SARSCoV-2 antibody tests, the authors retrospectively analysed antibody patterns amongst BP Healthcare employees to plane out the learning curve in understanding SARS-CoV-2 antibodies. In addition to determining seroprevalence of employees against SARS-CoV-2, the study also aims to compare antibody levels between vaccine types; between demographic determinants; between infected with noninfected employees; and to determine antibody concentration trends against time. To the authors' knowledge, this is the first study that compares SARS-CoV- 2 antibody patterns between multiple vaccine types in multi-ethnic Malaysia. 


\section{MATERIALS AND METHODS}

\section{Study design and ethics}

This is a retrospective cross-sectional study involving employees of BP Healthcare, a private healthcare service provider in Malaysia, who have had their SARS-CoV-2 antibodies analysed in BP Clinical Lab, Glenmarie from $1^{\text {st }}$ July 2021 to $30^{\text {th }}$ September 2021. This study population was targeted for its largely healthy population who were vaccinated with different types of vaccines. Furthermore, antibody tests had already been performed as part of staff benefit, making retrospective analysis more accessible.

Subject demographics, vaccination status, vaccine type, date of completed vaccination, history of COVID-19 and clinical history were obtained using a survey form whilst SARS-CoV-2 IgG Spike (RBD), IgG Nucleocapsid, IgM Spike and SARS-CoV-2 RT-PCR results were retrieved from the laboratory information system (LIS) and exported to Microsoft Excel. Repeat test results belonging to the same subject were included during extraction. Subjects with incomplete results, missing clinical information, rejected samples and/or denied consent were excluded from analysis.

As part of company policy, all employees are required to undergo periodical SARS-CoV-2 RT-PCR testing paid for by the company. Extracted RT-PCR results performed around the time of antibody testing are compared to the subject's survey response to confirm infection status.

This study was granted ethical approval by the Medical Research and Ethics Committee (MREC), Ministry of Health Malaysia with registration number NMRR-21-1693-61219.

\section{Measurement of analytes}

The SARS-CoV-2 IgG Spike (RBD) test is a quantitative test that detects antibodies towards the receptor binding domain (RBD) of the S1 viral protein by chemiluminescent immunoassay. Levels above $50 \mathrm{AU} / \mathrm{mL}$ confer a "DETECTED" result. A negative or "NOT DETECTED" test is reported when antibody levels are below $50 \mathrm{AU} / \mathrm{mL}$. This method includes the detection of neutralizing antibodies where a previous study has shown $>95 \%$ correlation of IgG Spike (RBD) with neutralizing antibodies measured by plaque reduction assay (Gallais et al., 2021).

IgG Nucleocapsid and IgM Spike are qualitative automated tests that detect the presence of IgG against the Nucleocapsid protein and IgM against the Spike protein of SARS-CoV-2 respectively. Levels above $1.40 \mathrm{~S} / \mathrm{C}$ for IgG Nucleocapsid and $1.00 \mathrm{~S} / \mathrm{C}$ for IgM Spike confer a "DETECTED" result whilst levels below the cutoff are reported as "NOT DETECTED".

All three antibodies were measured by chemiluminescent immunoassay on the ARCHITECT Ci8200 system (Abbott Laboratories, Illinois) and underwent daily quality checks using manufacturer's QC material.

Subjects were classified as positive for past COVID-19 based on documented confirmatory tests as per current national recommendations.

\section{Sample size}

To determine significant difference between two proportions, a minimum sample size is determined based on the following calculations (Epitools, 2021):

$\begin{array}{ll}\text { Desired power (two-tailed): } & 0.80 \\ \text { Confidence level: } & 0.95 \\ \text { Proportion population 1, n1: } & 0.70 \\ \text { Proportion population 2, n2: } & 0.30 \\ \text { Ratio of sample sizes, n2/n1: } & 0.40 \\ \text { Minimum sample size, n1 } & =49 \\ \text { Minimum sample size, n2 } & =20 \\ \text { Total sample size } & =\underline{\mathbf{9 9}}\end{array}$

\section{Data analysis}

Two separate sheets were created on Microsoft Excel. In the first sheet, all antibody tests including repeats were grouped according to subjects $(N=148)$ and in the second sheet, subjects with repeat antibody tests were listed as separate entities according to testing dates $(N=174)$. The first sheet was created to avoid data skewing when analysing demographic data such as age, gender, ethnicity and information on vaccination/infection. The second sheet was used to assess correlation, median differences and time-dependent patterns involving non-demographic data. Subjects were also grouped according to post-vaccination time windows i.e., pre-, 0-30 days post-, 1-2 months post-, 2-4 months post-, 4-6 months post- and $>6$ months postvaccination.

Both sheets were then transferred and analysed separately on SPSS version 26 (Armonk, NY: IBM Corp). Data were tested for normality using the Shapiro-Wilk test. Normally distributed data were described as mean \pm standard deviation values and non-parametric data as median \pm interquartile range values.

Group medians were compared using the Mann-Whitney $U$ test or Independent-samples Kruskal-Wallis test (where applicable); correlation was analysed using the Spearman rank-order correlation coefficient and association between nominal categories were assessed using Chi Square test. To assess antibody concentration trends, a scatter plot of antibody values against time from last vaccine dose was plotted. A significance level of 0.05 was assumed for all analysed data.

\section{RESULTS}

A total of 156 subjects consented to participate in the study, 8 of which were excluded due to missing test results resulting in a final total of 148 subjects. 20 subjects had repeated their antibody tests twice and another 3 subjects thrice, giving a total of 174 antibody test sets. Young females largely formed the study cohort with a median age of 29.0 years and $76.4 \%$ gender dominance. While all subjects eventually completed 2 doses of vaccine, 3 antibody tests were conducted prior to completing vaccination, 2 of which belonged to a post-infection subject. A descriptive summary of the study cohort is provided in Table 1.

Based on the positive cut-off of $50 \mathrm{AU} / \mathrm{mL}$ for IgG Spike (RBD), all vaccinated employees without past COVID-19 infection were successfully seroconverted at 1-month postvaccination regardless of vaccine type. The only non-infected subject who tested for IgG Spike (RBD) prior to vaccination returned a negative result of $3 \mathrm{AU} / \mathrm{mL}$. The same subject's IgG Spike (RBD) later increased to $4256.5 \mathrm{AU} / \mathrm{mL}$ at day 14 post-Comirnaty vaccine. 
Table 1. Descriptive data of subjects

\begin{tabular}{|c|c|c|}
\hline \multirow{2}{*}{ Parameter } & \multicolumn{2}{|c|}{ Overall, $N=148$} \\
\hline & Median [IQR] & $N(\%)^{*}$ \\
\hline \multicolumn{3}{|l|}{ Demographics } \\
\hline Age, years & $29[24-35]$ & \\
\hline Female gender & & $113(76.4)$ \\
\hline \multicolumn{3}{|l|}{ Ethnicity } \\
\hline Chinese & & $84(56.8)$ \\
\hline Malay & & $55(37.2)$ \\
\hline Indians & & $9(6.1)$ \\
\hline \multicolumn{3}{|l|}{ Vaccination information } \\
\hline Pfizer-BioNTech (Comirnaty) & & $82(55.4)$ \\
\hline Oxford-AstraZeneca (ChAdOx1) & & $50(33.8)$ \\
\hline Sinovac-CoronaVac & & $15(10.1)$ \\
\hline Moderna COVID-19 & & $1(0.7)$ \\
\hline \multicolumn{3}{|l|}{ Clinical information } \\
\hline No past COVID-19 & & $131(88.5)$ \\
\hline Past COVID-19 & & $17(11.5)$ \\
\hline Category 1 & & $5(3.4)$ \\
\hline Category 2 & & $11(7.4)$ \\
\hline Category 3 & & $1(0.7)$ \\
\hline No medical comorbidities & & 136 (91.9) \\
\hline Underlying medical condition & & $12(8.1)$ \\
\hline
\end{tabular}

* Percentage calculated based on cohort total.

Excluding pre-vaccinated subjects (i.e., subjects who tested for antibodies prior to vaccination) and subjects with past COVID-19, Comirnaty vaccinees were found to have significantly higher IgG Spike (RBD) concentrations up to 4 months post-vaccination compared to ChAdOx1 and CoronaVac vaccinees $(P<0.01)$ (Figures 1 and 2$)$. Within one month of vaccination, Comirnaty vaccinees were found to have significantly higher IgM Spike levels $(P=0.02)$ and remained positive up to 2 months of vaccination whilst ChAdOx1 and CoronaVac vaccinees largely tested negative within 1 month. As for IgG Nucleocapsid, about half of CoronaVac vaccinees tested positive within 2 months of vaccination, declining to negative levels after 2 months. Medians could not be compared for subjects who tested $>6$ months post-vaccination due to insufficient group sample size.

All three antibodies were significantly raised in infected compared to non-infected subjects within 1 month of vaccination $(P<0.01)$ with IgG Nucleocapsid remaining within positive levels up to 4 months post-vaccination. IgM Spike levels were also observed to be higher in infected subjects and remained within positive levels up to 4 months of vaccination but without reaching statistical significance (Table 2).

Within the small group of subjects with past COVID-19 $(N=17)$, all three antibodies' median titers showed no significant difference between vaccinated and unvaccinated subjects throughout all time windows and vaccine types. After completing vaccination, $60.0 \%$ (9/15) of infected subjects had high IgG Spike (RBD) levels exceeding $10000 \mathrm{AU} / \mathrm{mL}$ compared to $8.4 \%(11 / 131)$ of vaccinated subjects without past COVID-19 (Figure 2A).

Upon excluding pre-vaccinated and infected subjects, Spearman bivariate analysis showed a weak negative correlation between age and IgG Nucleocapsid titers $(R=-0.22, P=0.01)$. No correlation was found between age and IgG Spike (RBD) and IgM Spike titers $(R=0, P=0.97$ and $R=0.08, P=0.31$ respectively). There was also no correlation demonstrated between medical comorbidity and IgG Spike (RBD) $(R=0.01, P=0.92)$, IgM Spike $(R=0.05, P=0.59)$ and IgG Nucleocapsid $(R=0.05, P=0.59)$. Females were found to have higher IgG Spike (RBD) median compared to males within 2-4 months post-vaccination ( 2431.8 vs. $596 \mathrm{AU} / \mathrm{mL}, P<0.01$ ) (Table 2). No significant difference in titers were found in other time windows. Subjects of Malay descendance were also found to have significantly higher IgG Spike (RBD) medians compared to Chinese subjects overall (2 651.4 vs. $1396.4 \mathrm{AU} / \mathrm{mL}, P<0.01)$. Although IgG Spike (RBD) were higher in Indians (3 $357.3 \mathrm{AU} / \mathrm{mL}$ ), the difference was not statistically significant compared to the Chinese $(P=0.06)$ or Malays $(P=0.80)$. Chi square test confirms no significant association between ethnicity with vaccination-to-test time windows, $X^{2}(8, N=157)=9.6, P=0.29$; and between ethnicity with vaccine type, $\left.X^{2}(6, N=157)=8.71, P=0.19\right)$.

\section{DISCUSSION}

The outbreak of COVID-19 has prompted an acceleration of vaccine development against SARS-CoV-2, the rollout of which have remarkably reduced infection and transmission rates (Bar-On et al., 2021). Within 6 months, approximately 2.4 billion doses of vaccine had been administered after the first vaccine was approved for emergency use by the Food and Drug Administration (Ritchie et al., 2020). Rapid development in SARS-CoV-2 serology assays shortly ensued. In Malaysia, 8 months from the initiation of the vaccination program, $74 \%$ of the population were fully vaccinated with predominantly Comirnaty followed by CoronaVac and ChAdOx1 (Basta \& Moodie, 2020).

A study has shown that natural immunity from previous infection confers longer lasting and better protection against reinfection compared to vaccine-induced immunity, with further increased protection in individuals both infected and vaccinated (Gazit et al., 2021). Reinfection following vaccination is not uncommon especially with variant breakthroughs or when infection occurs before or in the early phase of antibody development (Jain et al., 2021; La Raja et al., 2021; Shastri et al., 2021). A study by La Raja et al. (2021) showed that while antibody levels were higher in subjects vaccinated after natural infection, levels declined after 100 days of vaccination. Nonetheless, the risk and severity of reinfection is greatly reduced by up to $94 \%$ at 3 weeks following the second dose (Gohil et al., 2021). Considering the skewing effects of vaccination and infection on antibody titers, pre-vaccinated and infected subjects were excluded from analysis when comparing antibody results between groups.

Multiple factors contribute to the heterogeneous immune response towards SARS-CoV-2 and its vaccines. Studies have reported conflicting outcomes on the effect of age on seroconversion. While Ota et al. (2021) proved significantly lower IgG Spike (RBD) titers in those above 40 years old, another study only showed a weak negative correlation following the first dose which subsequently disappeared after boosting with a second dose (Wheeler et al., 2021). Our data failed to correlate IgG Spike (RBD) with age although this may be confounded by the cohort's narrow age range.

In our study, IgG Spike (RBD) levels within 2-4 months of vaccination were significantly higher in females compared to males. This finding is also reported in studies involving subjects across different nations, age groups and vaccine types (Heriyanto et al., 2021; Pellini et al., 2021; Terpos et al., 

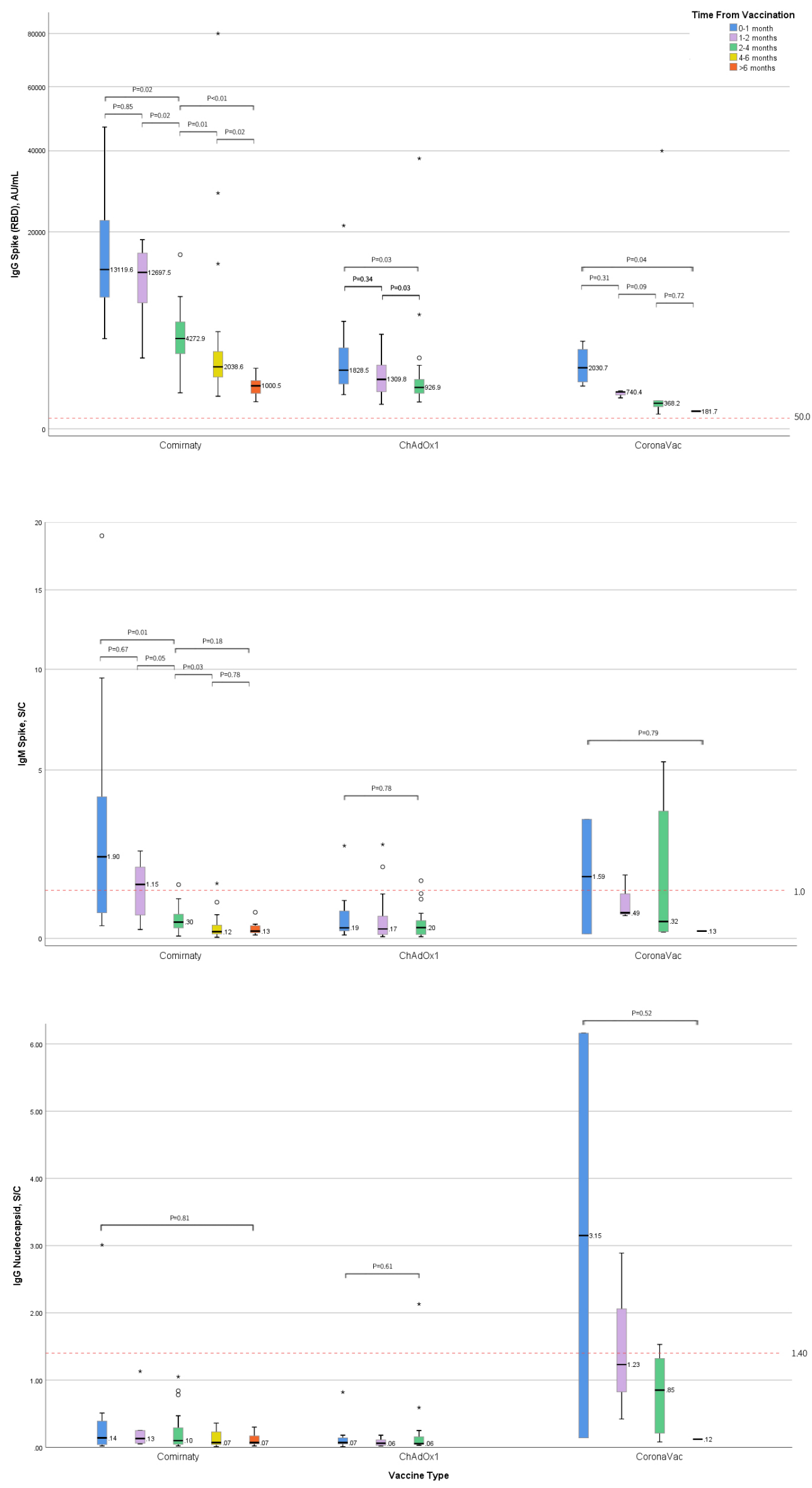

Figure 1. IgG Spike (RBD), IgM Spike and IgG Nucleocapsid levels amongst non-infected, vaccinated employees against time. Cut-off levels for positive results are shown in red dashed lines. The only subject vaccinated with Moderna is excluded. 


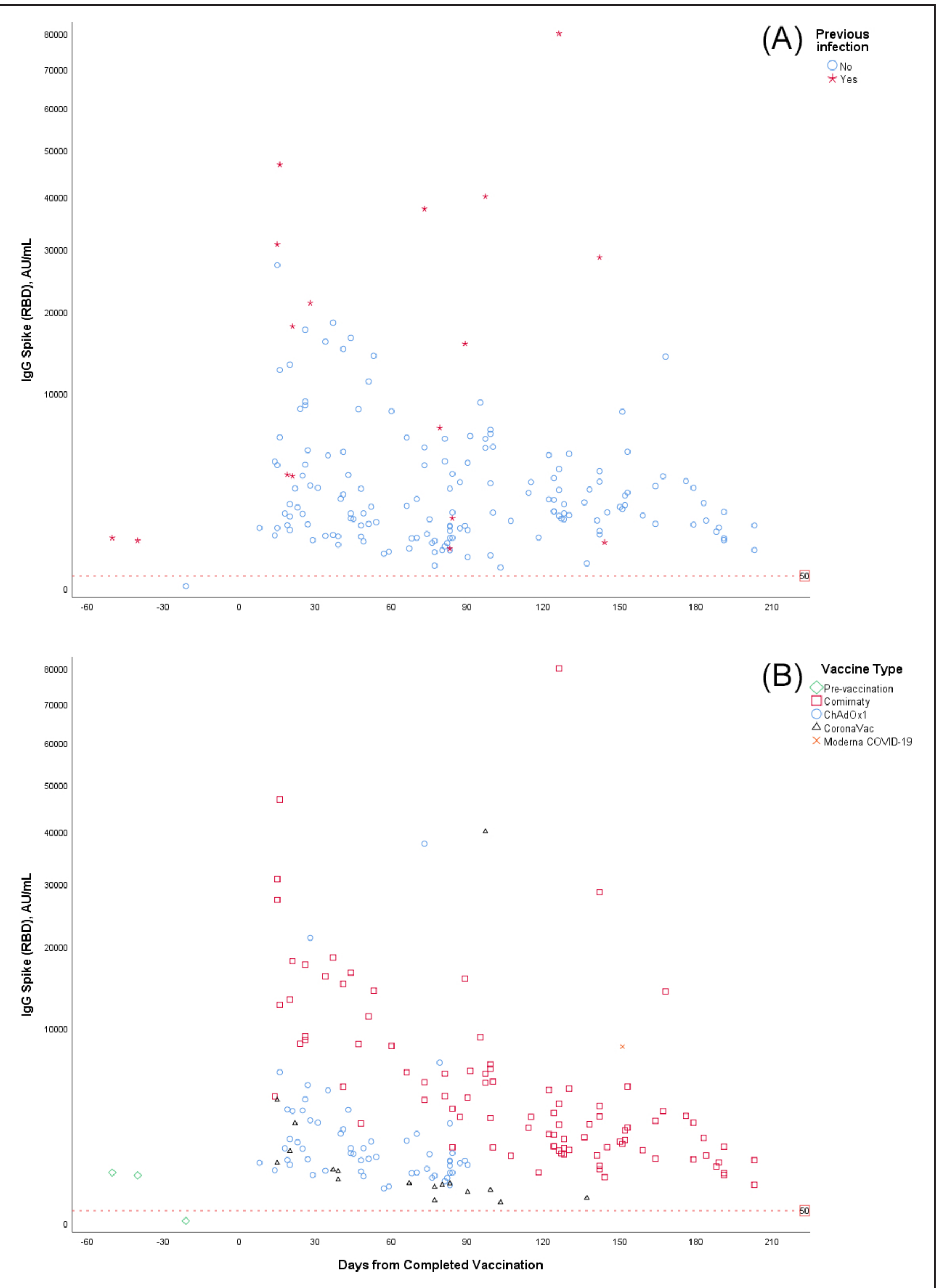

Figure 2. Scatter plot of IgG Spike (RBD) levels against time labelled according to (A) infection status and (B) vaccine type. Cutoff level for positive antibody is shown in red dashed lines. 
Table 2. Antibody titres according to clinical/demographic determinants and time from completed vaccination. Subjects with history of COVID-19 were excluded from gender and ethnicity analyses

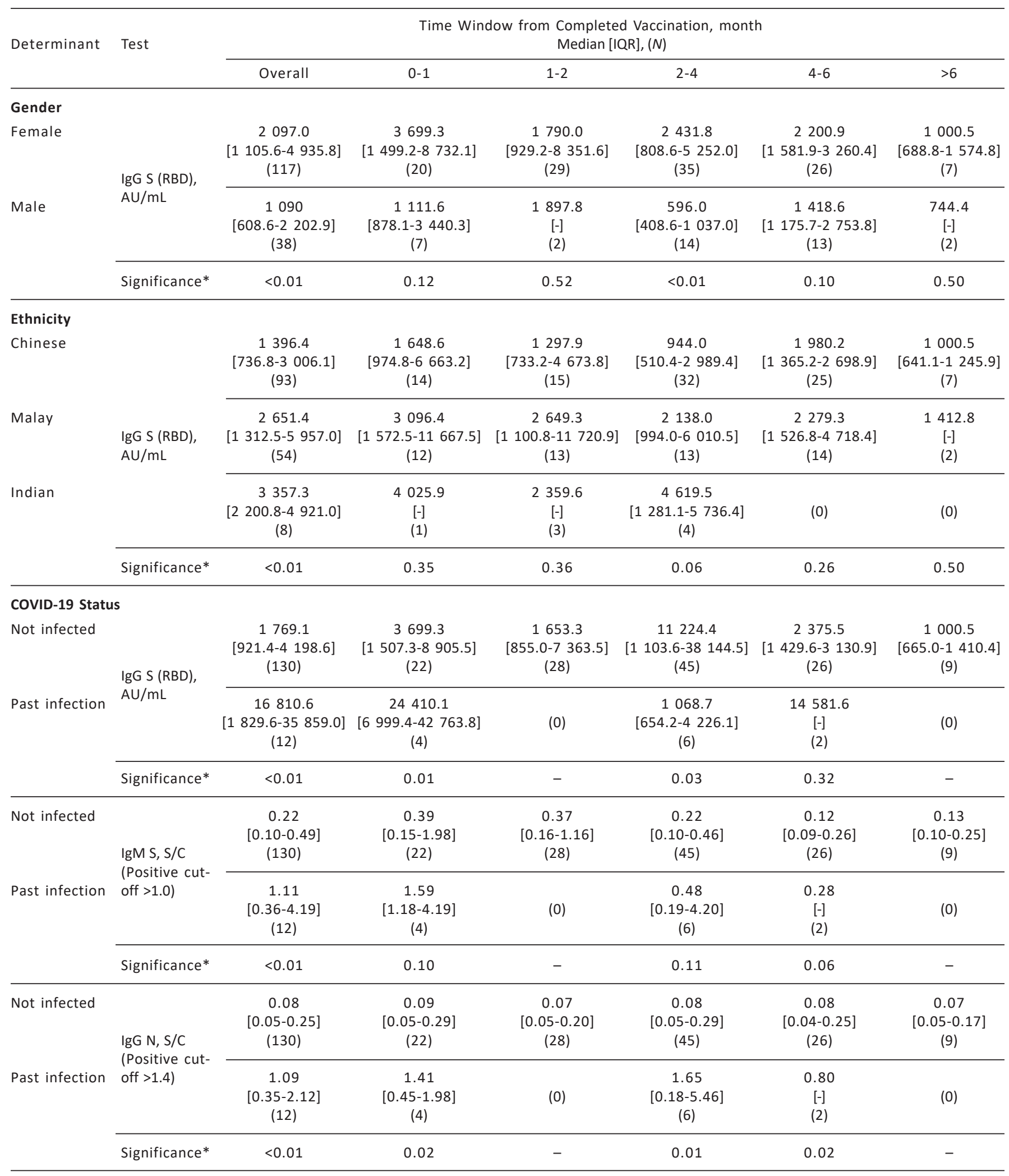

Abbreviations: IgG S (RBD), IgG Spike (receptor-binding domain); IgM S, IgM Spike; IgG N, IgG Nucleocapsid.

Median difference calculated using Mann-Whitney $U$ for 2-samples and Kruskal-Wallis 1-way ANOVA for multiple samples. Significance level is 0.05.

In view of the tests' qualitative nature, IgM S and IgG N median values are only shown for COVID-19 status for interest. 
2021). Most immune-regulating genes that encode both innate and adaptive signaling proteins are found on the $X$ chromosome and hormones such as estrogen and progesterone have been found to upregulate antibody responses, thus explaining gender-specific immune responses to vaccines/infections as well as predisposition to autoimmune diseases (Klein \& Flanagan, 2016; Ghosh \& Klein, 2017).

When ethnicity is concerned, COVID-19 predisposition is often linked to socioeconomic status and healthcare access (Smith et al., 2021a). However, in our systemically equal cohort, we found significantly higher IgG Spike (RBD) titers in Malay subjects compared to Chinese subjects. Although even higher titers in the Indian cohort were not statistically significant, its clinical significance is undetermined and is likely confounded by under-representation. Racedependent predisposition has long been established for various diseases thus genetic host component is implicated. Studies on various infectious diseases have shown genetic polymorphism involving toll-like receptors (TLR), vitamin $D$ binding proteins, human leukocyte antigens (HLA), cytokine receptors and epitope coverage that may contribute to the differential immune responses between ethnicities (Nahid et al., 2018; Smith et al., 2021b).

As the proportion of subjects with underlying disease is small and medically stable, our study did not show any association between medical comorbidity and antibody titers as previously published. Apart from medical diseases, other documented factors contributing to immune heterogeneity include past infection, immunosuppressive drugs, vaccine type and differential expression of host genes involved in viral infection (Bochnia-Bueno et al., 2021; La Raja et al., 2021; Ota et al., 2021; Prendecki et al., 2021).

To date, limited studies have compared immune responses induced by different types of vaccine. A recent systematic review showed that mRNA-based Moderna vaccine induced the highest levels of IgG Spike followed closely by Comirnaty, ChAdOx1 and inactivated virus vaccines (McDonald et al., 2021). Another study also showed higher IgG Spike levels in Comirnaty compared to ChAdOx1 vaccinees (BarrosMartins et al., 2021). Our study findings echo these studies although our lone Moderna vaccinee was excluded from most analyses. It is important to note, however, that antibody levels should not be used as a direct measure of immunity. Furthermore, the threshold of antibody titers in most studies were not well-defined despite its correlation in reducing infectivity and severity, thus its clinical effectiveness is inconclusive (Levin et al., 2021).

Cell-mediated immunity by T-cells and B-cells have been found to persist longer and confer additional protection to humoral immunity (Baraniuk, 2021; Kalimuddin et al., 2021; Khoury et al., 2021). Unlike short-lived neutralizing antibodies, T-cell responses towards SARS-CoV-2 last for six months and are speculated to persist for several years as per SARS-CoV-1 and MERS-CoV (Sariol \& Perlman, 2020). Human and animal studies have also demonstrated high SARS-CoV2-specific CD8+ cells, reduced viral load and reduced disease severity in infected subjects despite suboptimal antibody titers (Sewell et al., 2020; Noh et al., 2021). Given that immunity is based on antigen recognition, immune responses towards vaccination is expectedly similar to responses following natural infection (Sewell et al., 2020).

Depending on the class, antibodies take between 2-3 weeks to appear post-exposure with the short-lived IgM peaking 1-2 weeks earlier than IgG and turning negative within 20-90 days (Watson et al., 2020; Lau et al., 2021). Following Comirnaty vaccination, IgG Spike typically rises within 3 weeks, starts to decline at about 2 months and plateaus up to 3 months (Gervain et al., 2021; Trougakos et al., 2021). In our Comirnaty cohort, IgG Spike (RBD) levels steadily declined after 1 month, reaching low positive levels at 6 months of vaccination. A similar but attenuated pattern is seen in both ChAdOx1 and CoronaVac cohorts. Detectable IgG Nucleocapsid was more apparent in our CoronaVac cohort, corroborating with the vaccine's whole virus construct, and rapidly declined to negative levels after 1 month of vaccination given its shorter half-life compared to Spike antibodies (Gallais et al., 2021). Notably, IgG Spike (RBD) response was more robust than IgG Nucleocapsid following CoronaVac vaccine. This is supported by another study where $97 \%$ of healthcare workers seroconverted for the S1 protein and only $51.9 \%$ seroconverted for the $\mathrm{N}$ protein at 3 weeks post-CoronaVac (Bochnia-Bueno et al., 2021). It should be noted, however, that antibody assays are not standardized thus results are not comparable when assayed on different platforms.

Multiple studies have shown continuous declination in antibody titers over time, particularly in vulnerable populations such as the immunocompromised, medically ill and elderly (Levin et al., 2021; Lustig et al., 2021). In addition to this, the advent of highly transmissive mutants has instigated talks on booster doses and booster policies targeting groups with high-risk occupational exposure, compromised immunity and advanced age (Krause et al., 2021; Parums, 2021). Since July 2021, some countries had begun administering boosters including heterologous booster shots which resulted in elevated antibody titers as well as reduced infection rates and severe illnesses by a factor of 11.3 and 19.5 respectively (Bar-On et al., 2021; Bensouna et al., 2021; Patamatamkul et al., 2021). However, most studies largely involved non-pregnant, older, or medically ill adults, thus may not be applicable to the general population.

\section{Study limitations}

This study's cohort of largely young, healthy females limits analysis on age and health determinants. Subjects were also not followed up on an individual basis, thus data may not represent actual sequential changes in antibody titers and clinical endpoints cannot be determined based on antibody levels.

\section{CONCLUSION}

Seroconversion was successfully achieved in all vaccinated subjects regardless of vaccine type. The Comirnaty showed higher immunogenicity than ChAdOx1 and CoronaVac vaccines, with even higher antibody responses in convalescent subjects compared to COVID-19 naïve subjects. Antibody levels were also observed to be higher in females and certain ethnicities. Waning antibodies is apparent with time but should not be a direct measure of waning immunity as cell-mediated immunity is also a correlate of protection. As current evidence on booster dose outcomes is limited, more studies are required for verification.

\section{ACKNOWLEDGEMENTS}

The authors would like to thank all staff of BP Healthcare for their hard work and support. Also thanking the Director General of Health Malaysia for his permission to publish this article.

\section{Conflict of Interests}

The authors declare no conflict of interests. 


\section{REFERENCES}

Bai, Z., Cao, Y., Liu, W. \& Li, J. (2021). The SARS-CoV-2 nucleocapsid protein and its role in viral structure, biological functions, and a potential target for drug or vaccine mitigation. Viruses 13:1115. https://doi.org/10. 3390/v13061115

Bar-On, Y.M., Goldberg, Y., Mandel, M., Bodenheimer, O., Freedman, L., Kalkstein, N., Mizrahi, B., Alroy-Preis, S., Ash, N., Milo, R. et al. (2021). Protection of BNT162b2 vaccine booster against Covid-19 in Israel. New England Journal of Medicine 385: 1393-1400. https://doi.org/10.1056/ NEJMoa2114255

Baraniuk, C. (2021). How long does covid-19 immunity last? BMJ 373: n1605. https://doi.org/10.1136/bmj.n1605

Barros-Martins, J., Hammerschmidt, S.I., Cossmann, A., Odak, I., Stankov, M.V., Morillas Ramos, G., Dopfer-Jablonka, A., Heidemann, A., Ritter, C., Friedrichsen, M. et al. (2021). Immune responses against SARS-CoV-2 variants after heterologous and homologous ChAdOx1 nCoV-19/ BNT162b2 vaccination. Nature Medicine 27: 1525-1529. https://doi.org/10.1038/s41591-021-01449-9

Basta, N.E. \& Moodie, E.E.M. (2020). COVID-19 vaccine development and approvals tracker. McGill COVID19 Vaccine Tracker Team. https://covid19.trackvaccines.org/ country/malaysia/. Accessed 26 October 2021.

Bensouna, I., Caudwell, V., Kubab, S., Acquaviva, S., Pardon, A., Vittoz, N., Bozman, D.F., Hanafi, L., Faucon, A.L. \& Housset, P. (2021). SARS-CoV-2 antibody response after a third dose of the BNT162b2 vaccine in patients receiving maintenance hemodialysis or peritoneal dialysis. American Journal of Kidney Diseases [Preprint]. https://doi.org/10.1053/ j.ajkd.2021.08.005

Blain, H., Tuaillon, E., Gamon, L., Pisoni, A., Miot, S., Picot, M.C. \& Bousquet, J. (2021). Spike antibody levels of nursing home residents with or without prior COVID-19 3 weeks after a single BNT162b2 vaccine dose. JAMA 325: 18981899. https://doi.org/10.1001/jama.2021.6042

Bochnia-Bueno, L., De Almeida, S.M., Raboni, S.M., Adamoski, D., Amadeu, L.L.M., Carstensen, S. \& Nogueira, M.B. (2021). SARS-CoV-2 vaccination with CoronaVac: seroconversion rate in healthcare workers after 40 days. medRxiv [Preprint]. https://doi.org/10.1101/2021.05.20.21255825

Centers for Disease Control and Prevention (CDC). (2021). Interim Guidelines for COVID-19 Antibody Testing. Centers for Disease Control and Prevention. https://www.cdc.gov/ coronavirus/2019-ncov/lab/resources/antibody-testsguidelines.html.

Edara, V.-V., Pinsky, B.A., Suthar, M.S., Lai, L., Davis-Gardner, M.E., Floyd, K., Flowers, M.W., Wrammert, J., Hussaini, L., Ciric, C.R. et al. (2021). Infection and Vaccine-Induced Neutralizing-Antibody Responses to the SARS-CoV-2 B.1.617 Variants. The New England Journal of Medicine 385: 664-666. https://doi.org/10.1056/NEJMc2107799

Epitools. (2021). Sample size to detect a significant difference between two proportions. Ausvet. https://epitools.ausvet. com.au/twoproportions. Accessed 13 August 2021.

Gallais, F., Gantner, P., Burel, T., Velay, A., Planas, D., Wendling, M.-J., Bayer, S., Solis, M., Laugel, E., Reix, N. et al. (2021). Evolution of human antibody responses up to one year after SARS-CoV-2 infection. medRxiv [Preprint]. https:// doi.org/10.1101/2021.05.07.21256823
Gazit, S., Shlezinger, R., Perez, G., Lotan, R., Peretz, A., Ben-Tov, A., Cohen, D., Muhsen, K., Chodick, G. \& Patalon, T. (2021). Comparing SARS-CoV-2 natural immunity to vaccineinduced immunity: reinfections versus breakthrough infections. medRxiv [Preprint]. https://doi.org/10.1101/ 2021.08.24.21262415

Gervain, J., Szabó, K.B., Baki, E.H., Kadlecsik, L., Gyenesei, A., Herczeg, R. \& Simon, J. (2021). Monitoring of anti-SARSCoV-2 IgG antibody immune response in infected and immunised healthcare workers in Hungary: a real-world longitudinal cohort study. medRxiv [Preprint]. https:// doi.org/10.1101/2021.05.16.21257288

Ghosh, S. \& Klein, R.S. (2017). Sex Drives Dimorphic Immune Responses to Viral Infections, The Journal of Immunology 198: 1782-1790. https://doi.org/10.4049/jimmunol.1601166

Gohil, S.K., Olenslager, K., Quan, K.A., Dastur, C.K., Afsar, N., Chang, W. \& Huang, S.S. (2021). Asymptomatic and symptomatic COVID-19 infections among health care personnel before and after vaccination. JAMA Network Open 4: e2115980. https://doi.org/10.1001/jamanetwork open.2021.15980

Heriyanto, R.S., Kurniawan, A., Wijovi, F., Halim, D.A., Jodhinata, C., Marcella, E., Susanto, B., Wibowo, J., Indrawan, M., Heryadi, N.K. et al. (2021). The role of COVID19 survivor status and gender towards neutralizing antibody titers 1, 2, 3 months after sinovac vaccine administration on clinical year medical student in Indonesia. International Journal of Infectious Diseases 113: 336-338. https://doi.org/10.1016/j.ijid.2021.10.009

Jain, V.K., Iyengar, K.P. \& Ish, P. (2021). Elucidating causes of COVID-19 infection and related deaths after vaccination. Diabetes \& Metabolic Syndrome: Clinical Research \& Reviews 15: 102212. https://doi.org/10.1016/j.dsx.2021.102212

Kalimuddin, S., Tham, C.Y.L., Qui, M., De Alwis, R., Sim, J.X.Y., Lim, J.M.E., Tan, H.-C., Syenina, A., Zhang, S.L., Le Bert, N. et al. (2021). Early T cell and binding antibody responses are associated with COVID-19 RNA vaccine efficacy onset. Med 2: 682-688.e4. https://doi.org/10.1016/j.medj.2021. 04.003

Khoury, D.S., Cromer, D., Reynaldi, A., Schlub, T.E., Wheatley, A.K., Juno, J.A., Subbarao, K., Kent, S.J., Triccas, J.A. \& Davenport, M.P. (2021). Neutralizing antibody levels are highly predictive of immune protection from symptomatic SARS-CoV-2 infection. Nature Medicine 27: 1205-1211. https://doi.org/10.1038/s41591-021-01377-8

Klein, S.L. \& Flanagan, K.L. (2016). Sex differences in immune responses. Nature Reviews Immunology 16: 626-638. https://doi.org/10.1038/nri.2016.90

Krause, P.R., Fleming, T.R., Peto, R., Longini, I.M., Figueroa, J.P., Sterne, J.A.C., Cravioto, A., Rees, H., Higgins, J.P.T., Boutron, I. et al. (2021) Considerations in boosting COVID-19 vaccine immune responses. The Lancet 398: 1377-1380. https:// doi.org/10.1016/S0140-6736(21)02046-8

Lau, C.S., Phua, S.K., Liang, Y.L., Oh, M.L.H. \& Aw, T.-C. (2021) BNT162b2 mRNA COVID-19 vaccine elicited antibody responses in COVID-19-naïve subjects. Journal of Experimental Pathology 2: 117-127.

Levin, E.G., Lustig, Y., Cohen, C., Fluss, R., Indenbaum, V., Amit, S., Doolman, R., Asraf, K., Mendelson, E., Ziv, A. et al. (2021). Waning immune humoral response to BNT162b2 Covid19 vaccine over 6 Months. The New England Journal of Medicine. 385: e84. https://doi.org/10.1056/NEJMoa2114583 
Lustig, Y., Sapir, E., Regev-Yochay, G., Cohen, C., Fluss, R., Olmer, L., Indenbaum, V., Mandelboim, M., Doolman, R., Amit, S. et al. (2021). BNT162b2 COVID-19 vaccine and correlates of humoral immune responses and dynamics: a prospective, single-centre, longitudinal cohort study in health-care workers. The Lancet Respiratory Medicine 9: 999-1009. https:/ /doi.org/10.1016/S2213-2600(21)00220-4

La Raja, M., Pacenti, M., Grimaldi, I., Boldrin, C., Cattai, M., Solimbergo, E., Battisti, A., Scomazzon, M., Roman, A., Lazzaro, A.R. et al. (2021). COVID-19 convalescent plasma donors: impact of vaccination on antibody levels, breakthrough infections and reinfection rate. medRxiv [Preprint]. https://doi.org/10.1101/2021.07.13.21260414

McDonald, I., Murray, S.M., Reynolds, C.J., Altmann, D.M. \& Boyton, R.J. (2021). Comparative systematic review and meta-analysis of reactogenicity, immunogenicity and efficacy of vaccines against SARS-CoV-2. npj Vaccines 6: 74. https://doi.org/10.1038/s41541-021-00336-1

Nahid, P., Jarlsberg, L.G., Kato-Maeda, M., Segal, M.R., Osmond, D.H., Gagneux, S., Dobos, K., Gold, M., Hopewell, P.C. \& Lewinsohn, D.M. (2018). Interplay of strain and race/ ethnicity in the innate immune response to M. tuberculosis. PLOS ONE 13: e0195392. https://doi.org/10.1371/ journal.pone.0195392

Ni, W., Yang, X., Yang, D., Bao, J., Li, R., Xiao, Y., Hou, C., Wang, H., Liu, J., Yang. D. et al. (2020). Role of angiotensinconverting enzyme 2 (ACE2) in COVID-19. Critical Care 24: 422. https://doi.org/10.1186/s13054-020-03120-0

Noh, J.Y., Jeong, H.W., Kim, J.H. \& Shin, E.-C. (2021) T cell-oriented strategies for controlling the COVID-19 pandemic. Nature Reviews Immunology 21: 687-688. https://doi.org/10.1038/ s41577-021-00625-9

Ota, K., Murakami, S., Mukae, H., Kohno, S. \& Yanagihara, K. (2021). Measurement of multiple SARS-CoV-2 antibody titer after vaccination represents individual vaccine response and contributes to individually appropriate vaccination schedules. medRxiv [Preprint]. https://doi.org/10.1101/ 2021.05.21.21257575

Parums, D.V. (2021). Editorial: First full regulatory approval of a COVID-19 vaccine, the BNT162b2 Pfizer-BioNTech vaccine, and the real-world implications for public health policy. Medical Science Monitor 27. https://doi.org/10.12659/ MSM.934625

Patamatamkul, S., Thammawat, S. \& Buranrat, B. (2021). Induction of robust neutralizing antibodies against the COVID-19 Delta variant with ChAdOx1 nCoV-19 or BNT162b2 as a booster following a primary vaccination series with CoronaVac. medRxiv [Preprint]. https://doi.org/10.1101/ 2021.09.25.21264099

Pellini, R., Venuti, A., Pimpinelli, F., Abril, E., Blandino, G., Campo, F., Conti, L., De Virgilio, A., De Marco, F., Di Domenico, E.G. et al. (2021). Initial observations on age, gender, BMI and hypertension in antibody responses to SARS-CoV-2 BNT162b2 vaccine. EClinicalMedicine 36: 100928. https://doi.org/10.1016/j.eclinm.2021.100928

Prendecki, M., Thomson, T., Clarke, C.L., Martin, P., Gleeson, S., De Aguiar, R.C., Edwards, H., Mortimer, P., McIntyre, S., Lewis, S. et al. (2021). Comparison of humoral and cellular responses in kidney transplant recipients receiving BNT162b2 and ChAdOx1 SARS-CoV-2 vaccines. medRxiv [Preprint]. https://doi.org/10.1101/2021.07.09.21260192
Ritchie, H., Mathieu, E., Rodés-Guirao, L., Appel, C., Giattino, C., Ortiz-Ospina, E., Hasell, J., Macdonald, B., Beltekian, D. \& Roser, M. (2020). Coronavirus Pandemic (COVID-19). OurWorldInData.org. https://ourworldindata.org/coronavirus. Accessed 29 October 2021.

Sariol, A. \& Perlman, S. (2020). Lessons for COVID-19 immunity from other coronavirus infections. Immunity 53: 248-263. https://doi.org/10.1016/j.immuni.2020.07.005

Sewell, H.F., Agius, R.M., Kendrick, D. \& Stewart, M. (2020). Covid-19 vaccines: delivering protective immunity. BMJ 371: m4838. https://doi.org/10.1136/bmj.m4838

Shastri, J., Parikh, S., Aggarwal, V., Agrawal, S., Chatterjee, N., Shah, R., Devi, P., Mehta, P. \& Pandey, R. (2021). Severe SARS-CoV-2 breakthrough reinfection with delta variant after recovery from breakthrough infection by alpha variant in a fully vaccinated health worker. Frontiers in Medicine 8: 737007. https://doi.org/10.3389/fmed.2021. 737007

Smith, A.R., DeVies, J., Caruso, E., Radhakrishnan, L., Sheppard, M., Stein, Z., Calanan, R.M., Hartnett, K.P., Kite-Powell, A., Rodgers, L. et al. (2021a). Emergency department visits for COVID-19 by race and ethnicity - 13 States, OctoberDecember 2020. MMWR. Morbidity and Mortality Weekly Report 70: 566-569. https://doi.org/10.15585/mmwr.mm $7015 \mathrm{e} 3$

Smith, M., Abdesselem, H.B., Mullins, M., Tan, T.-M., Nel, A.J.M., Al-Nesf, M.A.Y., Bensmail, I., Majbour, N.K., Vaikath, N.N., Naik, A. et al. (2021b). Age, disease severity and ethnicity influence humoral responses in a multi-ethnic COVID-19 cohort. Viruses 13: 786. https://doi.org/10.3390/v13050786

Terpos, E., Trougakos, I.P., Apostolakou, F., Charitaki, I., Sklirou, A.D., Mavrianou, N., Papanagnou, E.-D., Liacos, C.-I., Gumeni, S., Rentziou, G. et al. (2021). Age-dependent and gender-dependent antibody responses against SARSCoV-2 in health workers and octogenarians after vaccination with the BNT162b2 mRNA vaccine. American Journal of Hematology 96: E257-E259. https://doi.org/10.1002/ ajh. 26185

Trougakos, I.P., Terpos, E., Zirou, C., Sklirou, A.D., Apostolakou, F., Gumeni, S., Charitaki, I., Papanagnou, E.-D., Bagratuni, T., Liacos, C.-I. et al. (2021). Comparative kinetics of SARSCoV-2 anti-spike protein RBD IgGs and neutralizing antibodies in convalescent and naïve recipients of the BNT162b2 mRNA vaccine versus COVID-19 patients. BMC Medicine 19: 208. https://doi.org/10.1186/s12916-021-020906

Watson, J., Richter, A. \& Deeks, J. (2020). Testing for SARS-CoV2 antibodies. BMJ 370: m3325. https://doi.org/10.1136/ bmj.m3325

Wheeler, S.E., Shurin, G.V., Yost, M., Anderson, A., Pinto, L., Wells, A. \& Shurin, M.R. (2021). Differential antibody response to mRNA COVID-19 vaccines in healthy subjects. Microbiology Spectrum 9: e00341-21. https://doi.org/10.1128/ Spectrum.00341-21 